\title{
INTERVENSI PLAY THERAPY UNTUK MENGATASI TRAUMA KEKERASAN PADA ANAK USIA DINI
}

\author{
Agit Purwo Hartanto ${ }^{(1)}$, Athia Tamyizatun Nisa ${ }^{(2)}$, Nur Astuti Agustriyana ${ }^{(3)}$ \\ Program Studi Bimbingan dan Konseling \\ Program Pasca Sarjana \\ Universitas Negeri Semarang \\ E-mail: agitpurwohartanto115@gmail.com
}

\begin{abstract}
Abstrak
Tujuan dari artikel ini adalah untuk mengkaji penggunaan intervensi play therapy dalam mengatasi trauma yang disebabkan oleh kekerasan yang dialami oleh anak usia dini. Berangkat dari kasus kekerasan anak yang semakin lama semakin memprihatinkan, maka dibutuhkan sebuah penanganan serius dan cocok untuk mengatasi trauma yang dialami anak. Anak usia dini adalah mereka yang berada di usia 2-3 tahun yang masih dalam tahap perkembangan. Semua aspek baik dari segi fisik, psikis, dan sosial yang belum matang membuat anak renta dengan trauma yang disesbabkan oleh kejadian yang tidak menyenangkan khususnya kekerasan. Pendekatan play therapy dirasa cocok untuk menangani anak yang mengalami trauma korban kekerasan karena anak memiliki masa bermain. Kenangan mereka dengan bermain membuat play therapy dapat dijadikan sarana untuk mengungkap kekerasan yang dialami anak secara lebih mendalam sehingga trauma dapat teratasi.
\end{abstract}

Kata kunci: play therapy, trauma kekerasan, anak usia dini

\section{Abstract}

The purpose of this article is to examine the use of play therapy interventions in overcoming trauma caused by violence experienced by young children. Departing from cases of child abuse is increasingly worried, it takes a serious and appropriate handling to overcome the trauma experienced by children. Early childhood is those who are in the age of 2-3 years who are still in the development stage. All aspects of the physical, psychological, and immature aspects of the body make the child vulnerable to trauma caused by unpleasant events, especially violence. Approach to play therapy feels appropriate to handle children who experienced trauma victims of violence because the child has a period of play. Their memories by playing make play therapy can be used as a means to expose the violence experienced by children in more depth so that trauma can be overcome.

Keywords: play therapy, violent trauma, early childhood

\section{Info Artikel}

Diterima Mei 2017, disetujui Mei 2017, diterbitkan Juni 2017 


\section{PENDAHULUAN}

Anak adalah tumpuan dan harapan orang tua. Anak juga diharapkan menjadi penerus bangsa sehingga wajib dilindungi dan diberi kasih sayang. Fakta berbicara lain dengan maraknya kasus kekerasan pada anak sejak beberapa tahun ini seolah membalikkan tuntutan bahwa anak harus dilindungi dan diberi kasih sayang. Jika bercermin pada pasal 28 b ayat 2 menyatakan bahwa "Setiap anak berhak atas kelangsungan hidup, tumbuh, dan berkembang serta berhak atas perlindungan dari kekerasan dan diskriminas", maka sudah seyogyanya anak menjadi obyek pemberian kasih sayang dan perlindungan serta terbebas dari kekerasan demi perkembangan optimal anal. Data berikut menunjukkan fakta bahwa kasus kekerasan yang dialami anak meningkat di setiap tahunnya.

Tabel 1. Data Kasus Pengaduan Anak Berdasarkan Klaster Perlindungan Anak KPAI Tahun 2011-2014

\begin{tabular}{|c|l|c|c|c|c|c|}
\hline \multirow{2}{*}{ No Klaseter / Bidang } & \multicolumn{4}{c|}{ Tahun } & \multirow{2}{*}{ Jumlah } \\
\cline { 3 - 7 } & & 2011 & 2012 & 2013 & 2014 & \\
\hline 1 & Kekerasan Fisik & 126 & 110 & 291 & 142 & 669 \\
\hline 2 & Kekerasan Psikis & 49 & 27 & 127 & 41 & 244 \\
\hline 3 & Kekerasan Seksual & 329 & 746 & 590 & 621 & 2286 \\
\hline 4 & Pembunuhan & 50 & 132 & 127 & 168 & 477 \\
\hline 5 & Pencurian & 15 & 118 & 92 & 89 & 314 \\
\hline 6 & Penculikan & 32 & 75 & 68 & 46 & 223 \\
\hline 7 & Kecelakaan Lalu Lintas & 14 & 161 & 97 & 76 & 348 \\
\hline 8 & Bunuh Diri & 12 & 35 & 17 & 23 & 87 \\
\hline 9 & Aborsi & 6 & 9 & 19 & 28 & 62 \\
\hline 10 & Kepemilikan Senjata Tajam & 0 & 25 & 45 & 55 & 125 \\
\hline 11 & $\begin{array}{l}\text { Penganiyayan, Pengroyokan dan } \\
\text { Perkelahian }\end{array}$ & 61 & 32 & 22 & 74 & 189 \\
\hline & TOTAL & & & & & \\
\hline
\end{tabular}

Dikutip : Komisi Perlindungan Anak Indonesia (KPAI) Bidang Data Informasi dan Pengaduan Tahun 2011

Beberapa kasus kekerasan pada anak juga marak diberitakan. Seperti kasus seorang anak umur 2,5 tahun di Bogor yang menjadi korban kejahatan seksual berupa pencabulan dan pemerkosaan. Lalu korban dibungkus dengan selimut lalu disembunyikan di dalam almari dan akhirnya meninggal karena tidak dapat bernafas. Pelaku tersebut adalah orang terdekat korban yang tidak lain adalah tetangga korban (news.liputan6.com, diakses tanggal 26 November 2016). Kemudian kasus penganiayaan anak yang dilakukan oleh pengasuh di sebuah kontrakan di Kampung Jati, Kota Depok. (news.liputan6.com, diakses tanggal 27 November 2016). Selanjutnya kasus kekerasan pada anak yang dilakukan orang tuanya sendiri di 
Kampung Momonot, Kabupaten Bogor hingga meninggal. Motif kekerasan tersebut dilakukan karena stress berat akibat orangtua terlilit hutang (news.liputan.com, diunduh 27 November 2016). Pelaku kekerasan pada anak bisa datang dari siapa saja, bahkan orang terdekat anak yaitu orang tua. Maka perlu menjadi perhatian bersama betapa ironis ketika pelaku kekerasan anak dilakukan oleh seseorang yang harusnya menjadi pelindung bagi anak.

Kekerasan merupakan perilaku yang merugikan baik untuk pelaku maupun korban terlebih lagi korbannya adalah anak yang masih berada pada usia dini. Theodore (2002: 77) menjelaskan kekerasan pada anak adalah istilah yang menggambar tindak kekerasan atau menciderai sehingga membuat anak menderita. Secara inklusif mengarah pada semua tindakan yang dilakukan oleh pengasuh anak yang merugikan, mengancam, dan menyakiti anak dalam proses pengasuhannya. Tindak kekerasan tersebut dapat berupa kekerasan fisik, seksual, psikologis, dan penelantaran. Dari penjelasan tersebut dapat disimpulkan bahwa salah satu dampak dari kekerasan adalah bahaya psikologis yang merujuk pada kondisi trauma. Hal ini berarti anak usia dini yang mengalami kekerasan akan mengalami kondisi traumatis. Kekerasan yang terjadi pada anak usia dini menjadi salah satu faktor terjadinya trauma hal ini dijelaskan oleh Blom (2004: 182) bahwa pemicu trauma di masa kanakkanak mencakup hal-hal antara lain pelecehan seksual atau pemerkosaan, kekerasan keluarga, dan penganiayaan fisik.

James (dalam Rymaszewska dan Philpot, 2006: 43) menjelaskan trauma psikologis terjadi ketika ada ancaman nyata yang dirasa membahayakan disertai ketidakmampuan seseorang untuk mengatasinya. Pada dasarnya setiap manusia memiliki kemapuan dalam mengatasi suatu hal yang disebut dengan coping. Namun jika ancaman dirasa lebih besar dari kemampuan mengatasi sesuatu maka akan menyebabkan trauma. Trauma yang terjadi pada anak akan berdampak sangat buruk. Seperti yang diungkap Powers, dkk (2016) bahwa trauma di masa anak usia dini dapat menjadi ingatan laten yang dapat muncul lagi di masa dewasa. Sehingga kekerasan anak menjadi perhatian penting untuk ditindaklanjuti dalam bentuk penanganan maupun pencegahan (Barthes dan Marc, 2016). Merujuk pada hal tersebut dapat dipahami bahwa anak yang menjadi korban kekerasan perlu mendapatkan perhatian serius terutama berkaitan dengan dampak psikis yang ditimbulkan sehingga perlu adanya proses penanganan secara komprehensif dan berkelanjutan.

Penanganan pada anak usia dini korban kekerasan yang mengalami trauma telah banyak dilakukan. Dalam konteks konseling salah satunya ada intervensi dengan bermain yang 
disebut dengan play therapy. Play therapy adalah pendekatan yang dimungkinkan untuk dapat membantu menyembuhkan trauma yang dialami oleh anak usia dini. Rakesh, Uma, dan Srinath (2010) menjelaskan bahwa play therapy dapat membantu konseli dalam konteks ini adalah anak usia dini untuk mereduksi kesedihan yang dialami karena kejadian yang tidak diinginkan yang kemudian menyebabkan kesedihan yang mendalam. Selanjutnya, Maslihah (2013) menjelaskan bahwa play therapy dapat mengidentifikasi kekerasan seksual yang dialami anak seperti diperolehnya informasi tentang lokasi dan kronologis kekerasan. Selain itu melalui play therapy anak dapat mengekspresikan perasaan marah sehubungan dengan kasus yang terjadi. Dengan demikian konselor dapat mengidentifikasi permasalahan dan keadaan yang dialami konseli dalam hal ini adalah anak usia dini. Sehingga dengan pendekatan konseling bernuansa bermain anak akan merasa senang dan terbuka terhadap konselor.

\section{PEMBAHASAN}

\section{Perkembangan Bermain Anak Usia Dini}

Manusia memiliki tahap tumbuh dan berkembangan dari mulai fase prenatal hingga fase tua. Dalam prosesnya terdapat fase anak usia dini (early childhood) yang berada pada usia 2-6 tahun (Zgourides, 2000: 53). Banyak yang mengistilahkan bahwa pada fase tersebut anak berada dalam masa keemasan (golden age). Masa keemasan diartikan sebagai masa dimana anak sangat mudah menerima rangsangan. Erikson dalam Ferist dan Ferist (2010: 301) menyebutkan masa tersebut sebagai masa bermain dimana anak mengembangkan daya gerak, keterampilan berbicara, keingintahuan, imajinasi, dan kemampuan menentukan tujuan.

Hal tersebut di dukung dengan perkembangan motoriknya dimana sitem syaraf otot telah berkembang sehingga memungkinkan anak untuk bergerak lebih aktif. Berkaitan dengan bermain, Desmita (2009: 141) juga membahasnya dalam perkembangan psikososial dimana perkembangan anak pada fase ini di dominan dengan aktivitas bermain. Bermain bagi anak menjadi hal yang menyenangkan dan bukan sebuah aktifitas yang membebani. Seperti yang diaungkap Hertherington dan Parke dalam Desmita (2009: 141) bahwa permainan bagi anak diartikan sebagai aktifitas yang tidak serius dan dibutuhkan oleh anak untuk memberi perasaan menyenangkan pada anak tersebut.

Kegemaran anak untuk bermain membuat anak membentuk hubungan dan persahabatan dengan teman seusianya. Hubungan yang terjalin dengan baik antara anak dan orang tua membuat anak lebih mudah membangun hubungan dengan temannya. Persahabatan pertama dibuat saat anak berusia 3 tahun, 
walaupun anak bisa bermain bersama sebelum usia tersebut. Sama seperti orang dewasa, anak cenderung mengembangkan persahabatan dengan anak-anak yang memiliki minat yang sama, disukai, menawarkan dukungan, dan serupa dalam ukuran dan penampilan. Persahabatan menciptakan kesempatan bagi untuk belajar bagaimana menghadapi situasi yang menimbulkan dendam, berbagi, belajar nilai, dan mempraktikkan perilaku yang lebih matang. (Zgourides, 2000: 67).

Fagen, Sylva, dan Pepler (dalam Cohen, 2006: 57) mengungkapkan beberapa manfaat yang didapat dari bermain yaitu dapat memberikan kemampuan untuk beradaptasi dengan lingkungan baru, membantu anak memecahkan beberapa jenis masalah, anak memiliki fleksibilitas yang lebih besar dalam pemecahan masalah dan solusi. Bates (2002: 310) menambahkan dengan bermain anak diberi kesempatan untuk terlibat dalam kegiatan konkret dan bermakna yang meningkatkan perkembangan fisik, bahasa, sosial, dan kognitif.

Saat bermain, anak dapat bertambah pengetahuan dan pemahaman diri, orang lain, dan dunia di sekitar mereka. Perkembangan motor anak menjadi semakin disempurnakan melalui aktivitas fisik seperti berlari, memanjat, dan melempar bola. Bermain juga penting untuk pengembangan keterampilan bahasa anak-anak. Saat bermain anak menggunakan kata-kata untuk mengekspresikan Pikiran dan gagasan. Selama bermain, anak-anak diberi kesempatan untuk berinteraksi sosial dengan teman sebayanya.

\section{Trauma Kekerasan}

Caruth (dalam Meek, 2010: 22) mendefinisikan trauma sebagai sebuah respon yang tertunda pada peristiwa atau kejadian yang luar biasa dalam bentuk halusinasi, mimpi, pikiran, atau perilaku yang berasal dari peristiwa tersebut. Sedangkan WHO (2002: 5) mendefinisikan kekerasan sebagai penggunaan fisik atau tenaga yang disengaja untuk mengancam atau melawan seseorang atau kelompok yang mengakibatkan luka, kematian, bahaya psikologis, perkembangan buruk, atau perampasan. Maka dapat diambil kesimpulan bahwa trauma kekerasan adalah respon yang tertunda dalam bentuk halusinasi, mimpi, pikiran, atau perilaku yang berasal dari peristiwa penggunaan fisik atau tenaga yang disengaja untuk mengancam. Kekerasan dapat berupa kekerasan fisik yang melibatkan melukai tubuh dengan tindakan seperti menendang, meninju, menusuk, atau memukul. Kekerasan emosional yaitu melibatkan melukai seorang dengan berteriak, mengancam, atau merendahkan nama anak dengan panggilan 'bodoh'.

Trauma memiliki tingkan tersendiri. Menurut Doctor dan Shiromoto (2010: 103) terdapat 3 tingkatan trauma dari yang ringan 
disebut tipe I hingga paling berat tipe III. Berikut adalah penjelasannya

1. Trauma Tipe I

Ditandai oleh reaksi akut terhadap pengalaman tunggal yang tidak terduga dan sangat traumatis yang sulit dilupakan karena adanya flashback, perilaku penghindaran, dan tingkat gairah yang tinggi.

2. Trauma Tipe II

Melibatkan kejadian kronis atau berulang terhadap kejadian traumatis

Selama periode waktu tertentu. Karena sifatnya kronis, korban sering bergantung pada keterampilan mengatasi seperti penyangkalan besar, mati rasa, disosiasi, atau kemarahan. kategori kedua didasarkan pada banyak peristiwa kekerasan yang meluas yang dimulai sejak usia dini dan berlanjut selama bertahun-tahun. Adanya pelanggaran batas yang parah seperti melibatkan banyak pelaku, penggunaan kekerasan, dan sadis. Biasanya pelecehan fisik dan seksual terjadi bersamaan dengan penyiksaan dan tindak kekerasan fisik dan seksual yang parah. Demikian juga, anak-anak yang dipukuli atau dipaksa melakukan tindakan seksual dengan pengasuh akan mengalami trauma tipe ini.

\section{Tipe III}

Korban mungkin merasa ingin bunuh diri dan putus asa tanpa alasan yang jelas. Gejala biasanya hebat, namun ingatan, emosi, dan sensasi tubuh individu sulit dikenali karena perilaku disosiatif otomatis mereka. Riwayat hidup klien dengan trauma tipe III biasanya dikotori dengan hubungan yang mengecewakan dan kasar, penghindaran keintiman, dan masalah kepercayaan utama. Sering ada pola somatisasi dan sering sakit kepala dan seringkali pmenyalahgunaan zat atau ketergantungan juga. Pengobatan bersifat kompleks, berjangka panjang, dan multiphasic.

\section{Play Therapy}

Play therapy adalah sebuah proses terapeutik yang menggunakan permainan sebagai media terapi agar mudah melihat ekspresi alami seorang anak yang tidak bisa diungkapkannya dalam bahasa verbal karena permainan merupakan pintu masuk kedalam dunia anak-anak (Hatiningsih, 2013). Homeyer dan Morrison (2008) mengungkapkan play therapy adalah cara yang efektif untuk menjawab kebutuhan kesehatan mental anak dan diterima secara luas sebagai intervensi yang berharga dan sesuai dengan tahapan perkembangan.

Schultz (2016) menjelaskan bahwa play therapy memiliki potensi yang lebih menjanjikan dari pada terapi menggunakan obat. Play therapy merupakan alternatif solusi dalam membantu anak traumatik dapat kembali pada pribadi yang sehat secara mental dan berkembang secara 
optimal. Ryan dan Edge (2011) menjelaskan bahwa perlunya arah pendekatan dalam play therapy. Non directive play therapy dipandang sebagai pendekatan yang mampu secara efektif untuk mengidentifikasi perasalahan anak.

Pada umumnya play therapy adalah sebuah terapi yang membantu anak untuk mengekspresikan dirinya, melakukan eksplorasi terhadap pikiran dan perasaan dan membuat mereka memahami lebih baik mengenai pengalaman hidup mereka. Bermain merupakan sebuah aktivitas natural yang di dalamnya terdapat aktivitas belajar, eksplorasi dan merupakan media yang sangat efektif dalam membantu anak untuk bisa lebih ekspresif. Play therapy dilaksanakan secara urut dan sistematis. Maka dari itu (Geldard dan Geldard (2012) menyebutkan fase/ tahapan dalam pelaksanaannya, yaitu sebagai berikut :

1. Fase penilaian awal

Fase penilaian awal adalah saat persiapan untuk terapi. Selama fase ini, dilakukan pengumpulan informasi tentang anak dan masalah anak. Informasi ini memungkinkan konselor membuat hipotesis tentang apa yang mungkin dilakukan pada anak. Fase penilaian awal juga mencakup bertemu dan membuat perjanjian dengan orang tua. Dengan berpegang pada hipotesis ini, selanjutnya proses konseling akan dimulai.
2. Proses konseling

a. Memilih media bermain yang tepat sebelum bertemu anak. Pemilihan ini didasarkan pada usia, jenis kelamin, karakteristik pribadi, dan jenis masalah emosional.

b. Bergabung dengan anak yang mempunyai kepribadian dan kebutuhan yang khusus dan unik. Beberapa mungkin sulit dilibatkan karena berbagai alasan. Anak yang masih sangat kecil mungkin belum mempunyai kemampuan bahasa yang cukup untuk dapat berkomunikasi dengan efektif. Proses "penggabungan" harus dibentuk agar memenuhi kebutuhan individual setiap anak, hal ini dapat menggunakan mediasi permainan agar dapat mencairkan suasana sehingga anak lebih mudah untuk terbuka.

c. Mengundang anak bercerita. Keterampilan konseling menggunakan komunikasi verbal saja biasanya tidak bermanfaat pada klien, khususnya jika anak mempunyai keterampilan komunikasi yang buruk, tingkat distres emosional yang tinggi, dan gangguan psikologi akut. Mengundang anak bercerita dan memungkinkan anak bercerita adalah komponen paling inti dan 
efektif dari setiap proses konseling anak.

d. Pemecahan masalah. Konselor seringkali perlu untuk membantu anak memecahkan isu-isu tertentu sehingga isu ini tidak lagi mengganggu. Ini dapat dilakukan melalui permainan dan/ atau memakai keterampilan konseling dan kadang-kadang melalui masukan edukasional. Jika isu ini sudah dipecahkan dengan tepat, anak akan bisa menjalin hubungan dengan orang lain secara lebihnyaman atau terbebas dari kecemasan, dan bisa ebih adaptif terhadap lingkungan sosial dan emosionalnya.

e. Pemberdayaan

anak. Pemberdayaan mencakup mengusai isu-isu yang ada, sehingga anak tidak lagi terganggu berlebihan oleh pikiran dan ingatan yang menimbulkan kecemasan dan gangguan dengan hubungan adaptif normal. Akibatnya, anak mulai mempunyai pandangan yang berbeda tentang dirinya sehingga rasa percaya diri dan hubungan sosialnya membaik. Jadi, anak mampu berintegerasi dengan lebih nyaman ke dalam dunia sosial dan emosionalnya.

f. Membantu anak berpikir dan berperilaku secara berbeda untuk menyelesaikan proses konseling, konselor mempunyai tanggung jawab untuk membantu anak belajar cara berpikir dan berperilaku yang baru, sehingga dapat lebih beradaptasi. Jika hal ini tidak terjadi, pola pikir dan perilaku anak cenderung menimbulkan distres lebih lanjut, dengan anak membutuhkan konseling lagi di kemudian hari untuk menangani hal tersebut.

Dalam kekerasan dan trauma yang dialami oleh anak, konselor bisa menggunakan terapi bermain atau play theraphy yang lebih digemari oleh anak, menurut Mashar (dalam penerbitan) banyak teknik yang dapat digunakan dalam Play theraphy, diantaranya :

1. Symbolic play techniques

Merupakan permainan yang secara simbolik memungkinkan anak untuk mengeluarkan kehidupan emosi mereka melalui permainan.

2. Play techniques using natural media

Permainan yang menggunakan media alam seperti pasir, batu, daun palm, salju atau kristal es. Hal ini mengingat bahwa bahanbahan alam memiliki arti/ makna bagi anak dan memiliki nilai terapeutik.

3. Drawing and art techniques

Dengan melukis seseorang dapa memproyeksikan dan mengekspresikan fantasi dan asosiasi bebas. 
4. Story telling, role playing, and imagery techniques.

Permainan ini dapat mengeluarkan konflik didalam diri, mengenalkan cara adaptasi yang lebih sehat, dengan bertujuan untuk memunculkan insight, menanamkan nilai-nilai, dan keterampilan menyelesaikan masalah.

5. Electronic techniques

Permainan elektronik dapat menjadi alat untuk mengembangkan kemampuan menyelesaikan masalah, mengendalikan meningkatkan agresi, kemampuan berpikir, kerjasama dan nilai-nilai interpersonal.

Instrumen yang digunakan dalam sebuah terapi bermain pun tidaklah selalu permainan mahal. Contoh-contoh instrument yang dapat digunakan seperti, mainan small figures, pasir dan air, musik, clay, craft maupun puppets. Apapun mainan yang digunakan, yang terpenting adalah dapat membantu anak untuk mengekspresikan pikiran dan perasaan melalui metafora permainan. Beberapa teknik yang dapat digunakan dalam terapi bermain adalah visualiasasi kreatif, story telling, memahat, role play, menari dan bergerak, serta menggambar. Kreativitas yang tinggi sangat diperlukan dalam sebuah terapi bermain.

Membuat permainan dari barang bekas maupun mainan-mainan edukasi yang dibuat sendiri bersama anak pun dapat menjadi sebuah kegiatan yang menguatkan hubungan orang tua dan anak. Agar proses terapi bermain ini dapat berjalan efektif, yang terpenting adalah membuat anak merasa nyaman, aman dan mau untuk mengikuti terapi bermain, sehingga anak dapat bermain lebih percaya diri dan mudah untuk berbagi apa yang dirasakan ketika bermain. Hubungan positif yang terjalin dalam bermain dapat membantu perkembangan kognitif anak serta tingkah laku yang lebih positif.

\section{PENUTUP \\ Kesimpulan}

Intervensi play therapy dirasa sangat cocok diterapkan pada anak usia dini yang menjadi korban kekerasan. Anak usia dini yang berada pada usi 2-6 tahun memiliki karakteristik aktivitas bermain. Bagi anak usia tersebut bermain menjadi aktivitas yang diminan dan dilakukan dengan senang. Kondisi tersebut yang menjadikan play therapy dapat diandalkan dalam menangani anak korban kekerasan. Anak korban kekerasan Kekerasan yang dialami anak sudah jelas dapat merengut masa depan anak. Kondisi anak yang masih berusia dini dan masih butuh banyak berkembang menambah dukungan bahwa kekerasan pada anak adalah hal yang buruk. Selain itu anak akan menjadi renta mengalami trauma.

Proses konseling play therapy dapat dilakukan dengan memilih media bermain yang tepat, bergabung dengan anak, mengundang anak 
bercerita, pemecahan masalah, pemberdayaan anak, dan membantu anak berpikir dan berperilaku. Sedangkan Permainan yang diterapkan dalam play therapy dapat berupa Symbolic play techniques, Play techniques using natural media, Drawing and art techniques, Story telling, role playing, and imagery techniques, dan Electronic techniques.

\section{Saran}

1. Bagi orang tua

Orang tua adalah pihak yang paling dekat dengan anak hendaknya dapat meluapkan kasih sayang kepada anak serta melindungi anak dari ancaman kekerasan. Selain itu orang tua diharapkan dapat menemani anak dalam bermain sehingga terjalin ikatan yang kuat antara orang tua dan anak.

2. Bagi Konselor

Konselor menjadi pihak yang dilibatkan dalam penanganan anak ketika ada masalah. Dalam hal ini berkaitan dengan masalah trauma pada anak hendaknya konselor memeiliki keterampilan untuk menguasi konseling play therapy agar dapt diaplikasikan pada penanganan anak yang mengalami trauma kekerasan.

\section{DAFTAR PUSTAKA}

Ariany, T. 2013. Faktor-faktor Penyebab Terjadinya Kekerasan terhadap Anak oleh Orang tua dalam Rumah Tangga Ditinjau dari Kriminologi di Kota
Pontianak. Jurnal Gloria Yuris Vol 1, No 2 (2013).

Bates, J. W. 2002. "Play" dalam Salkind, N. J. (Ed), Child Development. New York: Macmillan Reference USA.

Blom, R. 2004. The Handbook of Gestalt Play Therapy. London Publishers: Jessica Kingsley.

Cohen, D. 2006. The Development of Play. London: Routledge.

Corey, Gerald. 2013. Theory and Practice of Counseling and Psychotherapy. USA: Seth Dobrin.

Desmita. (2009). Psikologi Perkembangan. Bandung: PT Remaja Rosdakarya.

Doctor, R. M. \& Shiromoto, F. N. 2010. The encyclopedia of Trauma and Traumatic stress disorders. New York: Facts On File Publishing.

Ferist \& Ferist. 2010. Teori Kepribadian. Jakarta: Salemba Humanika.

Fitriana,Y., Pratiwi, K., dan Sutanto, A.V. 2013. Faktor-Faktor yang Berhubungan dengan Perilaku Orang tua dalam Melakukan Kekerasan Verbal terhadap Anak Usia Pra-sekolah. Jurnal psikologi undip Vol.14 No.1 april 2015, halaman 81-93.

Geldard, K. \& Geldard, D. 2012. Penanganan Anak Dalam 
Kelompok. Yogyakarta : Pustaka Pelajar. .

Hatiningsih, Nuligar. 2013. Play Therapy untuk Meningkatkan Konsentrasi pada Anak Attention Deficit Hyperactive Disorder (ADHD). Jurnal Ilmiah Psikologi Terapan Vol. 01 No. 2, Agustus 2013 Hal 324-342 ISSN: 2301-8267.

Homeyer, L.E. and Morrison, M.O. 2008. Play Therapy "Practice, Issues, and Trends". American Journal of play: Trustees of the University of Illinois.

http://www.kpai.go.id. Data Kasus Pengaduan Anak Berdasarkan Klaster Perlindungan Anak KPAI Tahun 2011-2014. Diakses tanggal 27 November 2016.

Indriyani, Iin. 2011. Play Therapy: Pembelajaran Mitigasi Bencana Tanah Longsor untuk $A B K$. Bulletin Vulkanologi dan Bencana Geologi Volume 6 Nomor 3 Desember 2011: 7-15.

Marc, B dan Barthes, A. 2016. Children : Psysical Abuse. Encyclopedia of Forensic and Legal Medicine (Second Edition). Volume 4 Halaman 513-527. Elsivier.

Mashar, R. (dalam penerbitan). Konseling Pada Anak Yang Mengalami Stress Pasca Trauma Bencana Merapi Melalui Play Therapy. Magelang: Universitas Muhammadiyah Magelang.
Maslihah, S. 2013. Play Therapy dalam Identifikasi Kasus Kekerasan Seksual terhadap Anak. Jurnal Penelitian Psikologi 2013, Vol. 04, No. 01, 21-34.

Meek, A. 2010. Trauma and Media. London: Routledge.

Motte, J.L. 2011. Psychotherapeutic Techniques and Play Therapy with Children Who Experienced Trauma: A Review of The Literature. Journal Undergraduate Review Article 15 Volume 7 halaman 68-72. : Bridgewater State University

Pasal 28B ayat (2) UUD 1945

Powers, A., Fani,N., Cross, N., Ressler, K.J., dan Bradley, B. (2016). Childhood trauma, PTSD, and psychosis: Findings from a highly traumatized, minority sample. Child Abuse \& Neglect 58 (2016) 111-118

Ray, D.C. 2007. Impact of play therapy on parent-child relationship stress at a mental health training setting. British Journal of Guidance \& Counseling Vol. 36, No. 2, May 2008, 165-187.

Rakesh, A., Uma., dan Srinath, S. 2010. Play Therapy: Voice of a Silent Scream. J. Indian Assoc. Child Adolesc. Ment. Health 2010; 6(1):13-18.

Ryan., V. dan Edge., A. 2011. The role of play themes in non-directive. Journal Clinical Child 
Psychology and Psychiatry 17(3) 354-369.

Rymaszewska, J \& Philpot, T. 2006. Reaching the Vulnerable Child Therapy with Traumatized Children. London: Jessica Kingsley Publishers.

Schultz, W. 2016. Child-Centered Play Therapy. Reason Papers 38, no. 1 (Spring 2016): 21-37.

Theodore, A. D. 2002. "Child Abuse" dalam Salkind, N. J. (Ed), Child Development. New York: Macmillan Reference USA.
WHO (World Health Organization). 2002. World Report on Violence and Health. Switzerland: WHO publications.

www.news.liputan6.com

Yoo, J.A. 2014. Racial variations in the link between domestic violence and children's behavioral outcomes. Children and Youth Services Review 44 (2014) 90-99 : Elsivier.

Zgourides, G. 2000. Developmental Psychology. New York: IDG Books Worldwide. 